\title{
The influence of approach and avoidance motor actions on food intake
}

\author{
JENS FÖRSTER* \\ Universität Würzburg and International University \\ Bremen, Germany
}

\begin{abstract}
Two experiments explored the effect of arm positions of approach and avoidance on food intake. In Experiment 1, arm extension, an expression of avoidance behavior, led to smaller food intake than arm flexion, an expression of approach behavior. In Experiment 2, this effect was found only for a delicious drink (i.e. orange juice), but not for a neutral drink (lukewarm water). Different theoretical accounts for explaining the findings are discussed. Copyright (C) 2002 John Wiley \& Sons, Ltd.
\end{abstract}

During the last two decades experiments demonstrating so-called 'automatic' influences on information processing and behavior have accumulated. Whereas most of the evidence has been gathered in the context of priming research, where semantic concepts are activated which then influence people's judgments, feelings and behavior (e.g. Higgins, Rholes, \& Jones, 1977), in parallel, research on facial or body feedback (in the following body feedback) demonstrated that subtle activation of certain expression patterns or motor actions can as well lead people's judgments and feelings unintentionally (e.g. Strack, Martin, \& Stepper, 1988). However, whilst research on priming demonstrated automatic influences on motivation as well as behavior (see, for example, Bargh, Chen, \& Burrows, 1996; Dijksterhuis \& van Knippenberg, 1998; Mussweiler \& Förster, 2000), evidence for body feedback yielding behavioral consequences is still scarce. In this paper the possibility is explored that subtle activation of muscles associated with approach versus avoidance behavior can directly influence people's behavior, namely their eating behavior. Let me briefly summarize existing research on body feedback, to see why expression patterns could influence behavior.

Research on body feedback provided considerable evidence for the direct influence of behavior on cognition (for reviews see Adelman \& Zajonc, 1989; Izard, 1990; Neumann \& Strack, 2000a). Here, a direct route of how behavior can affect cognition was proposed (see Zajonc, 1980); this route works beyond conscious mechanisms. Experiments accumulated showing that unobtrusively induced expression patterns influenced participants' reported feelings (e.g. Stepper \& Strack, 1993; Larsen, Kasimatis, \& Frey, 1992; Zajonc, Murphy, \& Inglehart, 1989), their subsequent judgments (e.g. Strack et al., 1988; Strack \& Neumann, 2000), their preferences for objects and products (e.g. Cacioppo,

*Correspondence to: Jens Förster, International University Bremen, Campus Ring 1, PO BOX 750561, D-28725 Bremen, Germany. E-mail: j.foerster@iu-bremen.de

Contract/grant sponsor: Deutsche Forschungsgemeinschaft.

Copyright (C) 2002 John Wiley \& Sons, Ltd.

Received 7 May 2002

Accepted 6 September 2002 
Priester, \& Berntson, 1993; Tom, Pettersen, Lau, Burton, \& Cook, 1991), their evaluation of strangers (Förster, 1998), their susceptibility to counterattitudinal messages (e.g. Cacioppo \& Petty, 1979; Petty, Wells, Heesacker, \& Cacioppo, 1983; Wells \& Petty, 1980), and their memories and encoding of positive versus negative events (Förster \& Strack, 1996; Förster \& Strack, 1997; Förster \& Strack, 1998; Riskind, 1983). Here is one example: participants who held a pen with their teeth to facilitate smiling rated cartoons as funnier than participants who held a pen with their protruding lips, which inhibited a smiling expression (Strack et al., 1988). Importantly, the facial expressions were unobtrusively induced, so that the effect appeared outside of participants' awareness. Thus, more conscious inference mechanisms ('I am smiling, therefore the cartoons must be funny') were ruled out for producing this effect, indicating a more direct connection between proprioceptive cues and cognition. The effects are also different from semantic priming because therefore the meaning of the behavior must be activated, which is not the case if participants are prevented from inferring the meaning of the induced behavioral pattern.

In addition to such body feedback effects, expression patterns can unconsciously influence people's thinking via cognitive tuning processes (Schwarz \& Bless, 1991). Cognitive tuning refers to the fact that negative affective cues can signal a situation of insecurity and danger, thus promoting risk averse, vigilant, cautious and perseverant processing styles; whereas positive affective cues can signal security, thus promoting explorative, risky and creative processing styles. Paralleling the predictions of cognitive tuning, Friedman and Förster $(2000,2002)$ proposed that internal cues that are associated with positive or negative hedonic states (yet that do not themselves elicit affect) can by dint of this internal association come to independently trigger differential processing styles, such as analytic reasoning or creative thinking.

In order to test this hypothesis, Friedman and Förster $(2000,2002)$ manipulated the extent to which non-affective bodily feedback was associated with either positive or negative hedonic states and then examined the effects of this feedback on cognitive processes related to creative insight. The manipulation of non-affective cues involved having participants perform either arm flexor contraction (by pressing upwards on a table) or arm extensor contraction (by pressing downward on a table) (see Cacioppo et al., 1993; Priester, Cacioppo, \& Petty, 1996). According to Cacioppo and his colleagues, arm flexion gives rise to bodily feedback associated with approaching positive stimuli, while arm extension gives rise to bodily feedback associated with avoiding negative stimuli (see also Förster, 1998; Förster \& Strack, 1997, 1998; Förster, Higgins, \& Idson, 1998; Neumann \& Strack, 2000b). This hypothesis is based on the learning-theoretical notion that over the course of a lifetime, arm flexion (where the motor action is directed toward the self) is repeatedly associated with acquiring or consuming desired objects (i.e. approach motivation), while arm extension (where the motor action is directed away from the self) is repeatedly associated with rejecting undesired objects (i.e. avoidance motivation). In a series of experiments, Friedman and Förster $(2000,2002)$ could show that arm flexion, relative to arm extension, facilitated the solution of tasks which contained important aspects of creative thinking such as the ability to break away from initial, context-driven (mis)interpretations of complex visual figures as well as to restructure the figures in order to detect hidden target patterns and to start mental search for new alternatives (Schooler \& Melcher, 1995). Additional support for a cognitive tuning interpretation was provided by an experiment in which arm extension, relative to arm flexion facilitated analytical reasoning, a domain of performance posited by cognitive tuning theory to benefit from a systematic, detail-oriented processing style (Schwarz \& Bless, 1991).

The present research, however is a first step to investigate whether behavior can be influenced by the motor actions of arm flexion and arm extension as well. As a behavior, food intake was chosen since it is easily influenced by situational factors (Rozin, 1996) and as a manipulation of approach and avoidance arm flexion and arm extension were chosen, since they are subtle and thus self-perception mechanisms or semantic priming effects can be ruled. It is assumed that an approach gesture such as 
arm flexion facilitates consumatory behavior, whereas an avoidance gesture like arm extension inhibits it. Therefore, in Experiment 1 participants were asked to either flex or extend their arms and food was offered within a context of a cover story.

\section{EXPERIMENT 1}

\section{Stimulus Material}

In order to find an attractive and delicious kind of food, ten research assistants pretested several snacks, different types of chips, popcorn, cookies, pretzels, etc. They had to decide whether they could afford those types of food and whether they liked them. A kind of chocolate cookie filled with sweet orange marmalade was judged to be the most delicious and luxurious and it was chosen for the study.

\section{Participants}

Twenty-four students of the University of Würzburg were recruited as participants for an ostensible evaluation of political TV programs. This cover story was used to disguise the true purpose of the experiment. Participants were tested individually, and DM 5,- (approximately $\$ 3$ at the time) were offered for participation. All participants were tested between 1 p.m. and 3 p.m. (after lunch) to make sure that none of them was hungry. They were randomly assigned to the conditions. Four participants were excluded, one suffered from diabetes, two were dieting, and one indicated severe stomach problems.

\section{Procedure}

Upon their arrival, participants were seated at a table that was placed in front of a television set. Participants were instructed to watch a political program for about 25 minutes, and to evaluate it afterwards in a media questionnaire. To prevent participants from inferring the meaning of their induced arm positions, that is, to provide a direct and subtle induction of regulatory focus by the arm positions (see Strack et al., 1988; Olson \& Hafer, 1990), they were told that physiological reactions of muscle activity would also be recorded as an ostensible objective measure of preferences. To that end participants were connected to an EMG; half had to place their left hand palm upward under the table (arm flexion) while the other half had to press it downward on a table (arm extension). ${ }^{1}$ Participants were also allowed to relax their arms if they wanted to, but to continue pressing whenever possible. A bowl containing twenty chocolate cookies was placed on the same table with the empty box and the brand name of the food. After connecting the participant to the EMG, the experimenter switched on the TV, where a political documentary was presented and left the room, without saying a word about the cookies. This was done to rule out the possibility of any interaction effects on participants' eating behavior (such as 'social facilitation', as demonstrated by Berry, Beatty, \& Klesges, 1985; Redd \& de Castro, 1992, or 'social inhibition', as discussed by Rozin, 1996). After 25 minutes, the experimenter entered the room, disconnected the participant from the EMG, took away the bowl, and presented the questionnaire containing the following questions about the program and the cookies:

\footnotetext{
${ }^{1}$ An anonymous reviewer pointed to the possibility that it might be more uncomfortable to drink or eat while extending the arm. Even though this alternative explanation can not completely be ruled out, it seems unlikely because German etiquette demands placing the palm on the top of the table in a similar manner while eating, whereas placing the palm underneath the table is a severe failure in terms of etiquette. Thus, convenience of arm positions works against the hypothesis.
} 
'How did you like the program?' (rating scale from $1=$ not at all, to $9=$ very much); 'How did you like the cookies?' (rating scale from $1=$ not at all, to $9=$ very much), and some questions about their mood ('How do you feel right now?' from $1=$ very bad to $9=$ very good), the pleasantness of the arm positions ('How pleasant was the arm position?' from $1=$ very unpleasant to $9=$ very pleasant), and the effort of maintaining the arm position ('How strenuous was the arm position?' from $1=$ not strenuous at all, to $9=$ very strenuous). These variables were included to see whether the arm positions affected judgments and mood that could be a mediator for the predicted effects. Participants were also asked whether they had had lunch prior to the test and all of them reported that they had. Participants were then asked for their hypothesis about the experiment. No one discovered its real purpose or the meaning of the arm position.

\section{Results}

Two-tailed $t$-tests were conducted comparing the mean numbers of the ratings and the amount of cookies consumed.

As predicted, participants in the arm flexion condition consumed more cookies $(M=2.60)$ than participants in the arm extension condition $(M=0.90), t(18)=2.34 ; p=0.031$. Arm positions did neither affect the taste ratings $\left.\left(M_{\text {arm extension }}=5.71 ; M_{\text {arm flexion }}=7.63\right) ; t(18)=1.38 ; p=0.191\right)$, nor the ratings of the political program $\left(M_{\text {arm extension }}=6.60 ; M_{\text {arm flexion }}=5.90 ; t(18)<1\right)$.

Participants' current mood $\left(M_{\text {arm extension }}=7.10 ; M_{\text {arm flexion }}=6.20 ; t(18)=1.25 ; p=0.227\right)$ was not influenced by arm positions, and arm extension was rated to be slightly more pleasant $(M=3.70)$ and less strenuous $(M=5.20)$ than arm flexion (pleasantness $M=2.80$; effort $M=5.90$ ), but both differences were not significant at the conventional $5 \%$ ( $t \mathrm{~s}<1.36, p \mathrm{~s}>0.196$, respectively).

Mood, pleasantness, effort and the ratings were entered as covariates in the analyses of cookie consumption. The differences in food intake still remained significant.

\section{Discussion}

The results of Experiment 1 demonstrate that arm positions of approach or avoidance directly influenced the amount of food intake. Participants were not aware of the effect and therefore the effect can be considered automatic. Quality of taste, mood, or reported feelings according to the analyses did not mediate the effect. However, here of course one has to be careful, since it is almost impossible to prove non mediation with the statistical tests at hand. In addition, the small sample sizes might have prevented identification of an actual correlation. Moreover, it is well possible that the arm positions caused some unconscious affect (see Neumann \& Strack, 2000b) which might have mediated the effects and which were simply not detected by the questionnaire.

However, the question remains whether one would observe similar effects for any kind of food. It has for example been shown that motor actions do not affect evaluation of strangers which are not valence compatible with the arm positions (Förster, 1998). Förster, for example, found an influence of arm flexion only on attractive portraits and an influence of arm extension only on unattractive portraits. That is in case of valence compatibility, judgments were assimilated however, in case of incompatibility, there were no effects of the arm positions. Therefore, in the following experiment half of the not thirsty participants were offered ice cold, delicious orange juice, while the other half was given lukewarm mineral water. Lukewarm water was chosen because pretests indicated its neutral valence. In addition, a control group was introduced in which participants received nonspecific instructions for positioning their arms to see whether arm positions inhibited or facilitated food intake. 


\section{EXPERIMENT 2}

\section{Pretest}

Twenty students from an introductory class in psychology at the University of Würzburg were asked what kind of tasty food they usually could not afford. From this pool of answers, a certain kind of orange juice was submitted to another pretest, where 20 students had to rate it or lukewarm mineral water on a 9 point rating scale ('How did you like the drink?' from $1=$ not at all, to $9=$ very much). As predicted, the lukewarm water was rated as less tasty $(M=4.5)$ than the orange juice $(M=7.9)$. The orange juice was at the time very popular and the most expensive orange juice in Germany.

\section{Participants}

Ninety-six students of the University of Würzburg were recruited for an ostensible memory experiment and offered 5,- DM (\$3) for their participation. Participants were randomly assigned to the conditions and were tested individually.

\section{Procedure}

To ensure that nobody entered the experiment thirsty, all participants were given a big glass of sparkling water before the actual experiment started. To reduce the salience of the event (it is unusual for participants in Germany to get any beverages before an experiment), the following scenario was invented: after participants arrived at the laboratory, the experimenters asked them to wait in front of the door for a minute because of problems with the video tape used in the study. The experimenters apologized for the inconvenience, went into the kitchen of the social psychology department, and returned with a glass ( 0.4 litre) of cold sparkling water, which they offered to the participants. All participants drank some of the water.

After approximately ten minutes of waiting, participants were allowed to enter the laboratory and asked to sit down on a chair that was facing a television set. In front of the chair was a table with a glass (0.5 litre) containing either ice cold orange juice or lukewarm water. The brand name of the orange juice was visible to all participants to signalize its luxury. To prevent participants from inferring the meaning of the behavior, this time the cover story referred to an investigation of the role of hemisphere activation in memory. Participants were told that there is evidence that right hemisphere activation leads, under some conditions, to more organized encoding processes than left hemisphere activation. However, research also showed that oftentimes the opposite is true, and that the evidence for one or the other theory of how hemisphere activation affects encoding was essentially mixed. The purpose of the experiment was therefore to shed light on highly contradictory results. All participants of the experimental conditions (arm flexion or arm extension) were then told that they were in the left hemisphere condition, and therefore had to press their right palm in an ostensibly standardized way: some were instructed to press their right palm upward under the table (arm flexion), some downward on the table (arm extension). Participants in the control group, who were given the same cover story, were told that they were in a control group and that they should feel free to move or place their palms in whatever direction or position they liked. Then, the experimenter turned on the video. Participants were asked to continue to press their palms, but were told that they were allowed to relax if they had to and to continue whenever it was possible for them. Then the experimenter left the room. After the 
30-minute documentary, participants were instructed to fill out a questionnaire that included ratings on the documentary ('How did you like the documentary?'), the drink ('How did you like the orange juice/the water?', both on scales from $1=$ not at all, to $9=$ very much), and questions about their mood, the pleasantness of the arm position, and the effort at maintaining the position, using the same rating scales as in the earlier experiments. Afterwards, participants were debriefed, thanked, and given their participation fee. Once again, none of the participants reported any crucial hypotheses or suspicions.

Accordingly, the experimental design was a $2 \times 3$-factorial comparing Drink (orange juice versus lukewarm water) and Arm positions (arm flexion; arm extension; unspecific instructions) between participants.

\section{Results}

\section{Food Intake}

The mean amount of consumed beverages (in g.) is presented in Table 1. Participants drank more orange juice $(M=289 \mathrm{~g})$ than water $(M=198 \mathrm{~g})$. Participants under arm flexion consumed the biggest amount $(M=294 \mathrm{~g})$, followed by participants in the control group $(M=230 \mathrm{~g})$, and participants who extended their arms $(M=207 \mathrm{~g})$. The statistical analyses $(2 \times 3$-ANOVA $)$ revealed a significant main effect for Drink, $F(1,90)=10.87 ; p<0.001$, and a main effect of Arm positions $F(1,90)=3.58$; $p<0.05$. However, this influence for arm positions was especially evident in the condition where participants were given orange juice, but not in the condition where water was offered. Participants to whom orange juice was offered drank most when they flexed their arms, followed by participants with unspecific instructions, and by participants who extended their arms. Among participants to whom water was offered, those who where allowed to hold their arms in whatever position they wanted drank the least amount; participants who were asked to flex their arms drank more; those who extended their arms consumed the largest amount. However, these differences appear negligible. Consistently, a significant two-way interaction between the two factors was found, $F(2,90)=5.92, p<0.01$. Simple comparisons revealed that, as predicted, only the following differences in the condition where orange juice was offered were significant: participants who flexed their arms consumed significantly more orange juice than participants who extended their arms $(t(45)=3.9 ; p<0.001)$. Participants who

Table 1. Mean amount of consumed beverage and standard deviations, mean evaluation of the documentary and the taste of the beverage, mean mood ratings, mean ratings of the pleasantness of the arm positions as a function of arm positions (arm extension, arm flexion, control), and the valence of the drink (positive versus neutral)

\begin{tabular}{|c|c|c|c|c|c|c|}
\hline \multirow{2}{*}{$\begin{array}{l}\text { Arm positions } \\
\text { Valence of the drink }\end{array}$} & \multicolumn{2}{|c|}{ Arm extension } & \multicolumn{2}{|c|}{ Arm flexion } & \multicolumn{2}{|c|}{ Control } \\
\hline & Positive & Neutral & Positive & Neutral & Positive & Neutral \\
\hline Amount of consumed beverage (in g) & $187(183)$ & $228(146)$ & $381(107)$ & $206(121)$ & $298(120)$ & $161(110)$ \\
\hline Evaluation of the documentary & $6.6(1.26)$ & $5.9(1.78)$ & $6.1(1.41)$ & $6.1(1.69)$ & $5.8(1.53)$ & $6.6(1.50)$ \\
\hline Taste ratings & $7.1(2.49)$ & $4.6(2.50)$ & $6.7(2.18)$ & $5.5(2.22)$ & $6.3(2.24)$ & $3.7(2.57)$ \\
\hline Mood ratings & $7.1(1.59)$ & $6.1(1.67)$ & $6.6(1.20)$ & $7.0(1.32)$ & $6.9(1.57)$ & $7.1(0.72)$ \\
\hline Pleasantness of the arm positions & $4.3(1.39)$ & $3.2(1.47)$ & $3.4(1.20)$ & $3.3(1.30)$ & - & —* \\
\hline Effort of the arm positions & $4.6(2.06)$ & $5.6(1.99)$ & $5.1(1.80)$ & $5.1(2.25)$ & - & —* \\
\hline
\end{tabular}

*These ratings were only obtained for the experimental conditions. Standard deviations in parentheses. 
extended their arms differed significantly from participants in the control condition $(t(45)=2.23$; $p=0.015)$, as did participants who flexed their arms $(t(45)=1.67 ; p<0.05)$. The differences in the condition where participants were given lukewarm water to drink were not statistically significant at the conventional 5\% $(t \mathrm{~s}<1.46)$.

Additional ANOVAS were conducted for the evaluation of the documentary, the taste of the beverages, and the reported feelings.

\section{Evaluations and Feelings}

Table 1 also presents mean evaluations for the television program and the food. Whereas there were no significant effects for the program, participants liked the orange juice $(M=6.67)$ more than the water $(M=4.60)$, yielding a significant main effect, $F(1,90)=18.14 ; p<0.001$. No other effects were significant on food evaluation, all $F \mathrm{~s}<1$. Table 1 also summarizes the mean mood, effort, and pleasantness ratings. There were no significant effects for mood, effort or pleasantness at the conventional $5 \%$ level.

\section{Additional Analyses}

To determine whether the mood ratings, the evaluation of the documentary, or the evaluation of the taste systematically influenced the observed interaction, an additional analysis was conducted, in which the five variables were entered as covariates. The interaction remained significant, ruling out those variables as potential mediators for the observed effect on food intake.

\section{Discussion}

As can be seen from Experiment 2, food intake of a delicious drink (orange juice) was influenced by arm positions, whereas no influence of body feedback was found for the neutral drink (water). This influence of the arm position was obtained for components of avoidance behavior as well as for components of approach behavior: Participants who were led to press their palm upward on the table drank more orange juice than participants who were asked to perform nonspecific arm positions; participants who were led to press their palm downward drank less than participants in the control condition. Moreover, no influence of body feedback can be observed for lukewarm water. Once again a mediation analysis did not show any mediation by current mood or evaluations. To be sure, the lacking effect of mood, however, does not mean that there was no effect of affects. Therefore, the sample size was too small and in general it is theoretically almost impossible to confirm non mediation by the statistical analyses used here. However, it seems that in this study as in Experiment 1, experienced affect as measured does not seem to be a necessary factor for getting the observed effects. Here, more research needs to be done with more implicit measures of affect in order to more carefully investigate the role of affect as a mediator.

\section{GENERAL DISCUSSION}

This research program was addressing a first-generation question: Is there an effect of motor actions on behavior? And the answer is yes. In two studies, a facilitative effect of arm flexion on food consume 
could be found. Also, some second generation questions could be addressed: When is there an effect? And here the answer seems to be that arm positions influence food intake especially in case of delicious or luxurious food. In this General Discussion section therefore, I will discuss the thirdgeneration question: Why is there an effect?

One candidate for a theoretical account is cognitive tuning, as described above. Arm flexion can signal a benign environment, therefore leading to exploration or consumption, whereas arm extension can signal a dangerous environment therefore leading to conservative strategies and defense. However, it is not easy to explain the effects of Experiment 2 by cognitive tuning alone. Why would a signal of a benign environment lead to more orange juice consume leaving intake of lukewarm water unaffected? From cognitive tuning models it is neither clear if positive cues signaling benign environments would lead to more consumption in general or to different kinds of consumption nor it is clear if negative cues signaling dangerous environments lead to less or no consumption or to different kinds of consumption.

The same basic problem carry other theories, which would predict even more direct influences of approach/avoidance systems on consumption. For example, Neumann \& Strack's (2000b) work on emotion which is based on Lang's theory on appetitive and defensive reflexes (e.g. Lang, Bradly, \& Cuthbert, 1990) focuses on the possibility that certain motor patterns activate motivational systems (for example in the brain, as Berridge and Winckielman, in press, argue or because there is a common code for sensory input and motor action, as Prinz, 1990 for example argues) which then automatically lead to behavioral tendencies (see also Förster \& Strack, 1996). In line with this reasoning, Berridge \& Winckielman (in press) report results, showing that participants exposed to subliminally presented happy faces drank more of a (fairly mediocre tasting) juice than participants having been exposed to angry faces. This effect however, only occurred for thirsty participants whereas for non-thirsty participants, the faces had no influence. The authors argue that unconscious emotions caused the effects via biopsychological mechanisms mediated by subcortical brain systems. The effect only occurs, however, if the drink has an initial incentive value, which is only true for thirsty participants. Even though these experiments seem to be similar to the ones here reported, they are different in many regards. First, it seems unlikely that the arm positions are specific to emotions. Second, note that the effect was observed with a mediocre drink and here only with thirsty participants, who wanted to quench their thirst. Third, and most important, the proposed biopsychological theories are again silent on why there should be an influence on tasty drinks for non thirsty participants but no such effect on neutral drinks. To be sure, I do not want to question the reported work and effects which can easily and elegantly be explained by biopsychological theories assuming simple approach/avoidance dichotomies, however, it seems to me that slightly different motivational processes worked in my studies, which, in parallel and independently might have produced the effects. ${ }^{2}$ Therefore, the following theory is proposed, which goes beyond valence or approach/ avoidance systems, namely, regulatory focus theory. Let me explain the theory in more detail.

Friedman and Förster $(2001)^{3}$ recently reframed their cognitive tuning account for their creativity effects in terms of regulatory focus theory (Higgins, 1997) which points to the possibility that the influence of affect on creativity may be mediated not by the phenomenological experiences of pleasure or pain associated with affective states (which is implied in the cognitive tuning model), but rather by the motivational orientations, or regulatory foci, which underlie these states (Friedman \& Förster,

\footnotetext{
${ }^{2}$ The following reasoning profited enormously from a discussion with Piotr Winkielman.

${ }^{3}$ Historically, the studies of Friedman and Förster (2000); Friedman and Förster (2002) were conducted before Friedman and Förster (2001). The discrepancy in years was due to different review processes and editorial constraints. Thus the revision (Friedman and Förster, 2001) of Friedman \& Förster's original work $(2000,2002)$ appeared before the appearance of an actual older paper.
} 
2001). Simply stated, regulatory focus theory posits two qualitatively distinct motivational orientations, a promotion focus, which entails motivation to attain nurturance (e.g. food), and a prevention focus, which entails motivation to attain security (e.g. shelter from harm). With regard to affective pleasure and pain, successful attainment of nurturance-related goals within a promotion focus engenders cheerfulness-related affect, whereas failure within a promotion focus leads to dejection-related affect. In contrast, successful attainment of security-related goals within a prevention focus engenders quiescence-related affect, while failure within a prevention focus leads to agitationrelated affect (Higgins, Shah, \& Friedman, 1997). Whereas the motivational orientation in a promotion focus, which is concerned with gains and non-gains, is eagerness, the motivational orientation in a prevention focus, which is concerned with losses and non losses, is vigilance (see for example, Förster, Higgins, \& Taylor Bianco, in press). Significantly, promotion motivation is posited to involve a relatively 'risky' processing style in which novel alternatives are eagerly and actively sought, whereas prevention motivation is posited to involve a relatively risk-averse and vigilant processing style in which repetition is favored over novelty and alternatives are carefully eliminated (Crowe \& Higgins, 1997; Liberman, Idson, Camacho, \& Higgins, 1999).

It is reasonable then to argue that cues associated with a promotion focus can signal a benign environment facilitating exploration whereas prevention cues signal a dangerous environment facilitating vigilance. Thus, in contrast to the cognitive tuning approach, a promotion or prevention focus can influence creative thinking independently of the effects of emotional experience. In a series of experiments regulatory focus cues were manipulated by administering tasks which activated semantic and procedural representations related either to seeking nurturance (i.e. promotion motivation) or to seeking security (i.e prevention motivation). More specifically, participants had to solve a maze task depicting a cartoon mouse trapped in the center for which they had to find the way out of the maze either to approach a piece of cheese (thus manipulating an approach promotion orientation) or to avoid an owl (thus manipulating an avoidance orientation). In brief, these experiments demonstrated that promotion cues, relative to prevention cues, bolstered insight problem solving, cognitive flexibility, and the ability to generate creative alternatives. Consequently, it is quite possible that rudimentary bodily stimuli such as arm flexion may be associated with a promotion focus, with the motivation to attain nurturance by approaching beneficial objects. In corresponding fashion, rudimentary bodily stimuli such as arm extension may be associated with a prevention focus, with the motivation to attain security by avoiding noxious stimuli. If so, these internally-produced, nonaffective stimuli may generally function as regulatory focus cues, cues which by virtue of their chronic association with promotion and prevention motivational orientations independently trigger the differential processing styles accompanying these orientations.

Both the 'mood as signal' and the 'motivational orientation as signal' approaches could predict effects of motor actions on behavior. However, in the experiments above, using different kinds of food, one could distinguish between deficit needs, which have been assumed to be associated with a prevention focus and growth needs, which have been assumed to be associated with a promotion focus (Maslow, 1955). For example, when hungry, food intake can be regarded as satisfying deficit needs, thus reflecting safety requirements, whereas when not hungry, it can have an explorative character, thus reflecting self actualization and growth. By manipulating the kind of food, possibly, a 'regulatory fit' or 'non-fit' might have been established (see Higgins, 2000), leading to the above results. From this perspective it could be assumed that promotion cues of arm flexion relative to prevention cues of arm extension facilitate food intake, because arm flexion signals a benign environment where exploration is an adaptive behavior. However, this would only be the case if the food fits the goal to explore the environment, that is if it is an exciting, luxurious or unique kind of food. Food that only meets deficit needs, such as for example lukewarm water or old bread would not be consumed when promotion cues are present. Under arm extension luxury food would then constitute a misfit, since it is not a means to 
ensure security. Here it is reasonable to assume that a misfit between participant's states and the food leads to an inhibition of food intake (see Higgins, 2000). This might be due to the fact that when cues signal lack of security, luxury food cues that do not satisfy the goal are only distracting from the goal (e.g. of seeking the source of the security). Thus, efficient self regulation would ask for inhibition. The results are in line with this reasoning: whereas regulatory fit (orange juice and arm flexion) facilitates food intake, regulatory misfit (orange juice and arm extension) inhibits it. However, in order to make such strong claims, more research is needed. First, more direct evidence is needed showing that regulatory focus was in fact induced by the arm positions. Moreover, experiments are needed where in addition to a promotion fit, a prevention fit is manipulated. Note, that in the above experiments participants were not hungry, so that the situation more likely signified a situation of exploration (tasting a luxurious drink). Thus, it would be useful to also manipulate a prevention focus by for example using hungry participants and food signifying deficit needs, like old bread or lukewarm water. In addition, other behaviors need to be investigated in order to demonstrate the scope of the effects. One possible domain could be achievement motivation, where recent research already demonstrated that regulatory fit increases motivational strength (see Higgins, 2000; Förster et al., 1998; Förster, Idson, \& Higgins, 2001). In one experiment, for example, it was shown that participants' performances in anagram tasks were better when they worked under gain and non gain instructions while flexing their arm or when they worked under loss and non loss instructions while extending their arm compared to participants in conditions of arm flexion and loss/non-loss instructions and conditions of arm extension and gain/non gain instructions. Whereas a prevention focus has been found to be concerned with loss and non loss, a promotion focus is concerned with gain and non gains. Thus, regulatory fit (arm flexion, gains/non-gains; arm extension, loss/non-loss) led to better performance than regulatory misfit (arm flexion, loss/non-loss; arm extension gain/non-gain). The present experiments on food intake extend these effects to tasks that are not related to achievement, that is no performance goals need to be explicitly activated in order to get facilitation or inhibition of behavior as a function of regulatory fit. Further research is needed to explore the scope of the effects for other kinds of behavior.

\section{CONCLUSIONS}

The effect has some characteristics of automatic effects. Participants were unaware of the way in which arm position is categorized (i.e. as a component of approach or avoidance), and of the determining influence of the body feedback on food intake. Moreover, motor actions led behavior even when participants were not intentionally evaluating the food, and even when they were only vaguely invited ${ }^{4}$ rather than explicitly instructed to consume the food.

Thus, the observed effects point to the efficacy and efficiency of human self-regulation in that different motivational states can be unconsciously activated thus preparing action. However, this automaticity, like most of the automatic effects known from recent psychological research, may also have disadvantages. For example, people in a promotion focus state of eagerness when on vacation might engage more often in (unhealthful) behaviors such as drinking alcohol or sunbathing than in healthy behaviors. And people who are (for whatever subtle reasons) in a prevention focus of vigilance might engage in excessively cautious behavior such as hypervigilant braking in traffic situations. Therefore, further research is needed to investigate when these processes are activated and when people can control them.

${ }^{4}$ In Germany, placing a bowl with food on a table where one is sitting means that one can serve oneself. 


\section{ACKNOWLEDGMENTS}

This research was supported by a fellowship from the Deutsche Forschungsgemeinschaft and by a grant from the Deutsche Forschungsgemeinschaft to Roland Neumann, Jens Förster, and Sabine Stepper on 'Experiential Representations'. The experiments were conducted at the University of Würzburg. Jens Förster is now at the International University Bremen. I would like to thank Markus Denzler, Bärbel Schöppner, Katrin Meier, Amina Özelsel, and Markus Schindler who served as experimenters. Special thanks go to Fritz Strack, who supported this research in all phases and gave invaluable suggestions, and to Ron Friedman, Sabine Stepper Lioba Werth and Piotr Winkielman for fruitful discussions. Kirils Jegorovs is gratefully acknowledged for editing the script.

\section{REFERENCES}

Adelmann, P. K., \& Zajonc, R. B. (1989). Facial experience and the experience of emotion. Annual Review of Psychology, 40, 249-280.

Bargh, J. A., Chen, M., \& Burrows, L. (1996). Automaticity of social behavior: Direct effects of trait construct and stereotype activation on action. Journal of Experimental Social Psychology, 71, 230-244.

Berridge, K. C., \& Winckielman, P. What is an unconscious emotion? (The case of unconscious liking). Cognition \& Emotion. (in press).

Berry, S. L., Beatty, W. W., \& Klesges, R. C. (1985). Sensory and social influences on ice cream consumption by males and females in a laboratory setting. Appetite, 6, 41-45.

Cacioppo, J. T., \& Petty, J. R. (1979). Effects of message repetition and position on cognitive response, recall, and persuasion. Journal of Personality and Social Psychology, 37, 489-498.

Cacioppo, J. T., Priester, J. R., \& Berntson, G. G. (1993). Rudimentary determinants of attitudes. II: Arm flexion and extension have differential effects on attitudes. Journal of Personality and Social Psychology, 65, 5-17.

Crowe, E., \& Higgins, E. T. (1997). Regulatory focus and strategic inclinations: Promotion and prevention in decision-making. Organizational Behavior and Human Decision Processes, 69, 117-132.

Dijksterhuis, A., \& van Knippenberg, A. (1998). The relation between perception and behavior, or how to win a game of trivial pursuit. Journal of Personality and Social Psychology, 74, 865-877.

Förster, J. (1998). Der Einfluß motorischer Perzeptionen auf Sympathie-Urteile attraktiver und unattraktiver Portraits.[The influence of motor perceptions on likeability judgments of attractive and unattractive portraits]. Zeitschrift für Experimentelle Psychologie, 45, 167-182.

Förster, J. Higgins, E. T., \& Idson, L. C. (1998). Approach and avoidance strength during goal attainment: Regulatory focus and the 'goal looms larger effect'. Journal of Personality and Social Psychology, 75, 11151131.

Förster, J., \& Strack, F. (1996). The influence of overt head movements on memory for valenced words: A case of conceptual-motor compatibility. Journal of Personality and Social Psychology, 71, 421-430.

Förster, J., \& Strack, F. (1997). Motor actions in retrieval of valenced information: A motor congruence effect. Perceptual and Motor Skills, 85, 1419-1427.

Förster, J., \& Strack, F. (1998). Motor actions in retrieval of valenced information II: Boundary conditions for motor congruence effects. Perceptual and Motor Skills, 86, 1423-1426.

Förster, J., Grant, H., Idson, L. C., \& Higgins, E. T. (2001). Success/failure feedback, expectancies, and approach/ avoidance motivation: How regulatory focus moderates classic relations. Journal of Experimental Social Psychology, 37(3), 253-260.

Förster, J., Higgins, E. T., \& Taylor Bianco, A. (in press). Speed/accuracy in performance: Tradeoff in decision making or separate strategic concerns? Organizational Behavior and Human Decision Processes.

Friedman, R., \& Förster, J. (2000). The effects of approach and avoidance motor actions on the elements of creative insight. Journal of Personality and Social Psychology, 79, 477-492.

Friedman, R., \& Förster, J. (2001). The effects of promotion and prevention cues on creativity. Journal of Personality and Social Psychology, 81, 1001-1013.

Friedman, R., \& Förster, J. (2002). The influence of approach and avoidance motor actions on creative cognition. Journal of Experimental Social Psychology, 38, 41-55. 
Higgins, E. T. (1997). Beyond pleasure and pain. American Psychologist, 52, 1280-1300.

Higgins, E. T. (2000). Making a good decision: Value from fit. American Psychologist, 55, 1217-1230.

Higgins, E. T., Roney, C., Crowe, E., \& Hymes, C. (1994). Ideal versus ought predilections for approach and avoidance: Distinct self-regulatory systems. Journal of Personality and Social Psychology, 66, 276-286.

Higgins, E. T., Rholes, W. S., \& Jones, C. R. (1977). Category accessibility and impression formation. Journal of Experimental Social Psychology, 13, 141-154.

Higgins, E. T., Shah, J., \& Friedman, R. (1997). Emotional responses to goal attainment: Strength of regulatory focus as moderator. Journal of Personality and Social Psychology, 72, 515-525.

Izard, C. (1990). Facial expressions and the regulation of emotions. Journal of Personality and Social Psychology, $58,487-498$.

Lang, P. J., Bradley, M. M., \& Cuthbert, B. N. (1990). Emotion, attention, and the startle reflex. Psychological Review, 97, 377-395.

Larsen, R. J., Kasimatis, M., \& Frey, K. (1992). Facilitating the furrowed brow: An unobtrusive test of the facial feedback hypothesis applied to unpleasant affect. Cognition and Emotion, 6, 321-338.

Liberman, N., Idson, L. C., Camacho, C. J., \& Higgins, E. T. (1999). Promotion and prevention choices between stability and change. Journal of Personality and Social Psychology, 77, 1135-1145.

Maslow, A. (1955). Deficiency motivation and growth motivation. In M. Jones (Ed.), Nebraska symposium \#1 on values (pp. 1-30). Lincoln, NB: University of Nebraska Press.

Mussweiler, T., \& Förster, J. (2001). The sex aggression link: a perceptual-behavior dissociation. Journal of Personality and Social Psychology, 79, 507-520.

Neumann, R., \& Strack, F. (2000a). Experiential and nonexperiential routes of motor influence on affect and evaluation. In H. Bless, \& J. P. Forgas (Eds.), The message within: The role of subjective experience in social cognition and behavior (pp. 52-68). Philadelphia, PA: Psychology Press.

Neumann, R., \& Strack, F. (2000b). Approach and avoidance: The influence of proprioceptive and exteroceptive encoding of affective information. Journal of Personality and Social Psychology, 79, 39-48.

Olson, J. M., \& Hafer, C. L. (1990). Self-inference processes: Looking back and ahead. In J. M. Olson, \& M. P. Zanna (Eds.), Self-inference processes: The Ontario symposium (Vol.6, pp. 293-320). Hillsdale, NJ: Erlbaum.

Petty, R. E., Wells, G. L., Heesacker, M., \& Cacioppo, J. T. (1983). The effects of recipient posture on persuasion: A cognitive response analysis. Personality and Social Psychology Bulletin, 9, 209-222.

Priester, J. R., Cacioppo, J. T., \& Petty, R. E. (1996). The influence of motor processes on attitudes toward novel versus familiar semantic stimuli. Personality and Social Psychology Bulletin, 22, 442-447.

Prinz, W. (1990). A common coding approach to perception and action. In O. Neumann, \& W. Prinz (Eds.), Relationships between perception and action (pp. 167-201). Heidelberg: Springer-Verlag.

Riskind, J. H. (1983). Nonverbal expressions and the accessibility of life experience memories: A congruence hypothesis. Social Cognition, 2, 62-86.

Redd, M., \& de Castro, J. M. (1992). Social facilitation of eating: Effects of social instruction on food intake. Physiology and Behavior, 52, 749-754.

Rozin, P. (1996). Sociocultural influences on human food selection. In E. O. Capaldi (Ed.), Why we eat what we eat: The psychology of eating (pp. 233-263). Washington, DC: American Psychology Association.

Schooler, J. W., \& Melcher, J. (1995). The ineffability of insight. In S. M. Smith, T. B. Ward, \& R. A. Finke (Eds.), The creative cognition approach (pp. 97-134). Cambridge, MA: MIT Press.

Schwarz, N., \& Bless, H. (1991). Happy and mindless, but sad and smart? The impact of affective states on analytic reasoning. In J. Forgas (Ed.), Emotion and social judgments (pp. 55-71). Oxford: Pergamon.

Stepper, S., \& Strack, F. (1993). Proprioceptive determinants of emotional and nonemotional feelings. Journal of Personality and Social Psychology, 64, 211-220.

Strack, F., Martin, L. L., \& Stepper, S. (1988). Inhibiting and facilitating conditions of the human smile: A nonobtrusive test of the facial feedback hypothesis. Journal of Personality and Social Psychology, 54, 768-777.

Strack, F., \& Neumann, R. (2000). Furrowing the brow may undermine perceived fame: The role of facial feedback in judgments of celebrity. Personality and Social Psychology Bulletin, 26, 762-768.

Tom, G., Pettersen, P., Lau, T., Burton, T., \& Cook, J. (1991). The role of overt head movement in the formation of affect. Basic and Applied Social Psychology, 12, 281-289.

Wells, G. L., \& Petty, R. E. (1980). The effects of overt head movements on persuasion: Compatibility and incompatibility of responses. Basic and Applied Social Psychology, 1, 219-230.

Zajonc, R. B. (1980). Feeling and thinking: Preferences need no inferences. American Psychologist, 35, $151-175$.

Zajonc, R. B., Murphy, S. T., \& Inglehart, M. (1989). Feeling and facial efference: Implications of the vascular theory of emotion. Psychological Review, 96, 395-416. 